\title{
A NECESSÁRIA SUPERAÇÃO DA DICOTOMIA NO DEBATE SÉRIES-CICLOS NA ESCOLA OBRIGATÓRIA
}

\section{CLAUDIA DE OLIVEIRA FERNANDES}

Professora adjunta da Escola de Educação e coordenadora do Programa de Pós-Graduação em Educação da Universidade Federal do Estado do Rio de Janeiro coff@uol.com.br

\section{RESUMO}

A organização da escola e a cultura escolar são abordadas na sua relação com a implantação dos ciclos, em especial, nas escolas públicas. Tal relação é construída para consubstanciar a afirmação de que é necessário superar a dicotomia estabelecida no discurso tanto de professores, quanto de formuladores de políticas ou até mesmo de políticos e da população em geral, no que tange à qualidade da educação escolar, em relação à organização da escola em séries ou em ciclos. O objetivo do estudo é apontar para a necessidade de romper essa dicotomia, muitas vezes presente no debate séries/ciclos, e argumentar a favor de sua superação para a construção de uma escola mais democrática e para todos.

DEMOCRATIZAÇÃO DO ENSINO - HISTÓRIA DA EDUCAÇÃO - POLITICA EDUCACIONAL REPETÊNCIA

\begin{abstract}
OVERCOMING THEDICHOTOMY IN RETENTION-PROMOTION DEBATE ON COMPULSORY SCHOOL. The organization of schooling and the school culture are discussed in relation to the introduction of social promotion by learning cycles, particularly in public school systems. This relationship is constructed to substantiate the statement that is necessary to overcome the dichotomy established on the discourse of teachers, policy-makers and even politicians, as well as general population, on the quality of education, as far as regards the organization of the school into grades or learning cycles with social promotion. This study aims to indicate the need to eliminate the dichotomy which is often present in this issue, and to argue in favor of overcoming it in order to build more democratic school for all and for everyone.

DEMOCRATIZATION OF EDUCATION - HISTORY OF EDUCATION - EDUCATIONAL POLICIES - GRADE REPETITION
\end{abstract}


O texto está estruturado da seguinte forma: inicialmente se chama a atenção para a organização da escola seriada, sua história e cultura e os elementos que se relacionam e influenciam a reorganização da escola em ciclos. Em segundo lugar, o texto problematiza a implantação dos ciclos no cotidiano da escola, no sentido de seu encontro com a cultura da escola seriada e com o habitus dos agentes do campo educacional. Por fim, são apresentadas argumentações a favor da qualidade da educação escolar, cujas fronteiras estão para além da forma como se organiza a escolaridade, seja em séries, seja em ciclos.

Diversas têm sido as experiências no Brasil que tentam reverter o quadro de fracasso escolar que tem como uma de suas causas os altos índices de reprovação e evasão nas escolas. Projetos político-pedagógicos de redes de ensino que instituem experiências que buscam romper com a reprovação de alunos ao longo do ensino fundamental, como sistemas de promoção automática e progressão continuada, têm sido mais constantes e provocado bastante polêmica entre educadores e a sociedade em geral. $O$ sistema seriado conjugado às sucessivas reprovações propicia a evasão escolar e a distorção idade/série, aspectos que comprometem o sistema educativo como um todo, seja do ponto de vista pedagógico, social e/ou econômico. Tais aspectos, que majoritariamente têm sido combatidos com políticas de promoção automática, mais recentemente, também têm sido tratados pela implantação do sistema de ciclos. Justifica-se que a estruturação da escolaridade em séries concorre para o fracasso sob o argumento de que a aprendizagem ocorre de forma diferenciada e em tempos distintos entre os sujeitos. Consideradas todas essas questões e comungando com a concepção de que a aprendizagem se dá de forma singular em cada sujeito, chamo a atenção para o fato de que nem a avaliação com suas práticas e formas de normatização, nem a seriação podem, sozinhas, ser tomadas como as causas do fracasso escolar. Em contrapartida, o ciclo também não pode ser tomado como a redenção para o fracasso - como muitas políticas educacionais sustentam. A concepção de escola que temos hoje deve, em seu conjunto, ser analisada e, talvez, assim, diante de mudanças estruturais, possamos reverter o quadro de fracasso escolar, entendido neste trabalho principalmente como a falta de cumprimento da escola com sua função social.

Conhecer como ocorreu a formação/organização da escola seriada é importante para entender os limites e as possibilidades da implementação dos 
ciclos na escola atual. É também de igual importância compreender a forma pela qual a cultura ou as culturas da escola influenciam de forma significativa qualquer proposta de mudança em suas práticas e organização. História e cultura devem ser consideradas em suas interfaces.

\section{ELEMENTOS CONCEITUAIS PARA AVANÇAR NO DEBATE SÉRIES/CICLOS}

A história da organização escolar não se deu de forma linear e evolutiva. Enguita (1989, p. I27-128) afirma que a história da educação, no que tange à organização das instituições escolares, "é uma sucessão de revoluções e contrarrevoluções". Para ele, não se pode entender as "escolas" pós-revolução industrial como uma consequência de um continuum das "escolas", "academias", "pedagogos" da Grécia. O caráter não linear da história da educação se faz importante para situar a história dos sistemas escolares e dos processos de escolarização, entendendo-os como produtos culturais, sociais e até mesmo econômicos e políticos da cada época.

Situa-se escolarização, nesse texto, no sentido empregado por Hamilton:

...é socialmente visível; produz aprendizagem que, por sua vez, foi moldada por modos de ensino formalizados e institucionalizados. [...] Há fundamentos para reivindicar a existência de "escolarização" sempre que haja evidência, entre outras coisas, de pessoal educacional distintivo (por exemplo, "professores"), instrumentos educacionais distintivos (por exemplo, "livros-textos") e instalações educacionais distintivas (por exemplo, "escolas"). (1992, p. I4-1 5)

No decorrer dos séculos XVIII e XIX, os sistemas escolarizados passaram a ter a importante função de ajudar a manter e mesmo criar configurações específicas do mercado de trabalho, mediante processos de regulação pedagógica e estrutural (Hamilton, 1992). Diferentemente de outras épocas, a escola passou a ser utilizada como um espaço/tempo de formação de uma subjetividade disciplinada para o trabalho na sociedade industrial capitalista. Ainda, segundo Hamilton, em meados do século XIX nos EUA, os processos de 
escolarização se relacionavam a uma forma de ensino de classe conhecida como "recitação". Na "recitação" de classe "simultânea" os alunos eram agrupados dentro de estruturas hierárquicas da escola "seriada" ou "unificada". Podemos afirmar, com base nos estudos de Hamilton, que a origem das classes seriadas está na base da escola de massa.

Fernández Enguita (1989, p. I 16) também se refere à escola seriada quando diz que "a escola mútua' havia mostrado ser capaz de ensinar o mesmo em menos tempo ou muito mais no mesmo tempo, e com maior economia de professores. Entretanto, o tempo veio a ser, não a variável dependente, mas a independente".

Tanto o método da recitação quanto o simultâneo partem de uma lógica de organização do tempo e do espaço da sala de aula adequada ao contexto da época, cuja industrialização fazia que os colégios, já com sua função social voltada para a certificação dos estudantes para o ingresso no mercado de trabalho, preparassem os estudantes num tempo adequado para sua entrada no mercado e também para a aprendizagem da disciplina e da ordem.

Essa função de regulação da ordem, de modelação dos estudantes, constituiu a matriz dos elementos de uma gestão de escola, cuja lógica se organizou a partir de um tempo e espaço bem definidos, lineares, quase imutáveis. Um tempo monocrônico, ou seja, um tempo que preconiza a realização de uma atividade de cada vez, em progressão linear. De acordo com Pinto,

... passa a ser o horário, e o completar o horário, aquilo que tem prioridade. [...] A conclusão da tarefa é o que conta. Verifica-se por isso uma grande ênfase na programação rigorosa, permitindo criar um programa meticuloso, por exemplo, que possibilite a seriação daquilo que é urgente e daquilo que pode ficar para depois. (200I, p.22)

O tempo passa a ser uma variável independente, como afirmou Enguita, e não dependente dos sujeitos, de suas necessidades ou interesses e seu conhecimento.

I. O que o autor chama de escola mútua diz respeito aos "métodos mútuo e simultâneo" de exposição, na França, em princípios do século XIX. 
Chamamos a atenção para os vários nomes atribuídos à escola seriada: escola "mútua", "unificada", de "classes simultâneas" ou de "recitação" e, por fim, "de massa" 2 . Todas essas maneiras de referência à escola seriada apontam a lógica com a qual a nossa escola atual foi originada. Muitas mudanças ocorreram ainda no século $X I X$ e ao longo do século $X X$ com a escola seriada. Outras variações e tentativas de organização e gestão escolar tentaram romper com a lógica de uma escola de massa, como, por exemplo, as escolas operárias, as escolas anarquistas, as escolas do povo, a conhecida Summer Hill, dentre outras. No entanto, a escolarização que predominou, que se universalizou, foi a escolarização de massa, com uma organização seriada do tempo, do espaço e do conhecimento escolar.

No Brasil, a escolarização de massa, no sentido aqui empregado, começa a se institucionalizar ainda na primeira metade do século XIX com a laicização do ensino e a separação da Igreja e do Estado quanto à instrução. Também nessa época, as escolas protestantes passam a se expandir. No entanto, em I 882, segundo Perin e Laplane, a escola primária obrigatória, gratuita e leiga, berço fértil para a escolarização de massa, ainda era, na visão de Rui Barbosa, um sonho. Perin e Laplane (2002) afirmam que até o início do século XX, no Brasil, o processo de criação de uma escola de instrução pública era solicitado por um professor titulado ou não, ou por um grupo de moradores de uma comunidade após a certificação de que havia um número suficiente de alunos para se abrir uma escola com uma única classe: eram suficientes, em média, 45 alunos. $\bigcirc$ Estado deveria fiscalizar, remunerar o professor, pagar o aluguel do local de funcionamento e fornecer material didático e mobiliário. Um professor dava aulas numa mesma turma para "classes" diferentes e ele mesmo organizava os grupos de alunos e os conteúdos de acordo com o ritmo de aprendizagem dos estudantes. A passagem de uma classe para outra poderia ocorrer em qualquer época do ano, de acordo com avaliação feita pelo professor. No entanto,

...novas metodologias começaram a ser divulgadas e os serviços de inspeção escolar passaram a atuar como serviços de orientação pedagógica. Os ares de

2. Refiro-me à educação de massa no sentido do ensino voltado para as grandes plateias, de forma unificada, num mesmo tempo e espaço. 
modernidade tinham chegado à escola e as novas regras capitalistas sinalizavam para a necessidade de formação de um novo trabalhador. Os grupos escolares representavam, então, a superação do atraso, enquanto que a produção das escolas isoladas simbolizava um passado que deveria ser ultrapassado. Foi adotado, então, o regime de seriação, uma vez que a escola brasileira não era seriada em sua origem. (Perin, Laplane, 2002, p.5)

Analisando-se do ponto de vista histórico-social, há, portanto, uma lógica que foi sendo construída com base na organização da escola seriada, fruto de uma construção histórica, que se expressa hoje pelas ações e pelos habitus dos agentes do campo educacional, ou seja, dos professores, supervisores, educadores em geral.

Bourdieu (1997) corresponde o que acontece em um campo ao habitus dos agentes que se inter-relacionam em seu interior. Estando o habitus relacionado ao conceito de campo, podemos entender que funcione como um princípio que organiza, dá sentido e conforma as práticas dos agentes no interior dos campos e que, portanto, o habitus tanto diz respeito às práticas individuais quanto coletivas.

Sendo uma disposição interna e estruturada no social, o habitus se constitui no coletivo, ao mesmo tempo em que conserva as realidades individuais, pois a realização de tarefas diferenciadas é possível graças às transferências de esquemas construídos pelos agentes.

No campo educacional, podemos considerar que os professores incorporam certas disposições que conformam suas práticas a partir de uma lógica de funcionamento do trabalho escolar, bem como têm suas ações legitimadas socialmente. Para Bourdieu ( 1998), as práticas, conformadas através dos tempos, distintivas, naturalizam e legitimam as posições sociais que agentes ocupam nos diferentes campos.

No âmbito deste estudo, consideramos que a cultura da escola seriada se expressa no habitus dos agentes envolvidos no processo, no caso os docentes $^{3}$, mas também alunos e todos aqueles que passaram por processo de escolarização. Sendo o habitus constituído no passado, mas orientado para uma

3. Por docentes refiro-me aos professores, especialistas e direção: agentes que têm um envolvimento direto com o trabalho pedagógico da escola e com a sala de aula. 
ação no presente, este foi, portanto, constituído na vivência de uma escola que organiza seus tempos e espaços, seu currículo e avaliação com fundamento em uma lógica seriada, linear, cuja construção permanece até hoje. A proposta de reorganização dos tempos e espaços, de currículos e práticas avaliativas abala o habitus dos agentes e a cultura e lógica de funcionamento da escola. Entretanto, o habitus, ao ser um sistema em constante reformulação, não pode ser entendido apenas como algo sedimentado e imutável; é também um sistema de disposição construído continuamente e sujeito constantemente a novas experiências e aos estímulos conjunturais de um campo.

Da mesma forma que foi construída uma lógica que se esteia em uma cultura escolar seriada, a qual forneceu elementos para a constituição de uma disposição incorporada com base nessa própria cultura, pode-se imaginar que o habitus dos agentes possa transformar-se à medida que novas práticas incorporem-se à cultura da escola, instituindo uma nova lógica para a ordenação dos tempos e espaços escolares, para os conteúdos e seus tratamentos didáticos, como também para suas respectivas práticas avaliativas.

Uma outra via de análise do encontro entre escola seriada e escola de ciclos, complementar à anterior, entende a organização da escolaridade ${ }^{4}$ como um elemento constitutivo da cultura institucional, compreendendo cultura institucional no sentido empregado por Pérez Gómez:

O conjunto de significados e comportamentos que a escola gera como instituição social. As tradições, os costumes, as rotinas, os rituais e as inércias que a escola estimula e se esforça em conservar e reproduzir condicionam claramente o tipo de vida que nela se desenvolve e reforçam a vigência de valores, de expectativas e de crenças ligadas à vida social dos grupos que constituem a instituição escolar. (2001, p. 131 )

Para o autor, a cultura institucional é construída pela relação entre os aspectos macro e micro, isto é, a cultura institucional se dá na interação das políticas educacionais e a vida na instituição escolar, com destaque para a organização da instituição escolar, a cultura dos docentes e o seu desenvolvimento

4. Escolaridade: conjunto de anos a que os estudantes estão sujeitos ao longo de sua vida escolar. 
profissional. Para Pérez Gómez (1994) a cultura escolar se define mediante os papéis, normas, rotinas e ritos próprios da escola como instituição social.

Em Nóvoa (1995), a cultura organizacional é compreendida nas suas dimensões interna e externa, ou seja, tem uma configuração interna como também elementos que se estabelecem pela relação com a comunidade. Os elementos internos da cultura da organização são classificados pelo autor como visíveis e invisíveis. Estes últimos poderiam ser relacionados ao currículo oculto da escola e se constituem nos valores, crenças e ideologias presentes na instituição. Quanto aos elementos visíveis, o autor assim os subdivide: manifestações verbais e conceituais (fins e objetivos, currículo, linguagem, metáforas, "histórias", "heróis", estruturas etc.); manifestações visuais e simbólicas (arquitetura e equipamentos, artefatos e logotipo, lemas e divisas, uniformes, imagem exterior etc.) e manifestações comportamentais (rituais, cerimônias, ensino e aprendizagem, normas e regulamentos, procedimentos operacionais etc.).

Embora Forquin (1993) trabalhe com o conceito de cultura da escola e Gimeno Sacristán (1996) trabalhe com o conceito de cultura escolar e apresentem algumas distinções em suas definições, ambos utilizam o conceito de cultura baseado nos aportes da Antropologia para explicar o que se passa no interior da escola, em seu cotidiano. Consideram a cultura como um elemento estruturante do cotidiano de um grupo social, expressando seu modo de agir, de relacionar-se, seus hábitos, crenças, valores etc. Gimeno Sacristán (1996) entende que a cultura escolar se revela pela "cultura vivida" nas salas de aula, confundindo-se com o currículo real. Para o autor (1996, p.34), a "cultura escolar é uma caracterização, ou melhor, uma reconstrução da cultura, feita em razão das próprias condições nas quais a escolarização reflete suas pautas de comportamento e organização".

Forquin (1993, p. 167) faz uma distinção entre cultura escolar e cultura da escola. Esta última se define no âmbito da escola, compreendida como "um 'mundo social', que tem suas características e vida próprias, seus ritmos e seus ritos, sua linguagem, seu imaginário. Seus modos próprios de regulação e de transgressão, seu regime próprio de produção e de gestão de símbolos". Já a cultura escolar representa o "conjunto de conteúdos cognitivos e simbólicos que, selecionados, organizados, 'normalizados', 'rotinizados', sob o efeito dos imperativos da didatização, constituem habitualmente o objeto de uma 
transmissão deliberada no contexto das escolas". O autor assinala que o tempo escolar, definido por ele como a divisão dos conteúdos e objetivos em séries, e estes redivididos em programações anuais, bimestrais, semestrais, e, ainda, o tempo organizado no planejamento das aulas, marca os saberes escolares tanto quanto os manuais e materiais didáticos, as notas e o controle da aprendizagem. A necessidade de didatização gera traços característicos dos saberes escolares: divisão formal dos conteúdos em capítulos, lições, resumos, sínteses etc. e para o autor "essas marcas caracterizam o produto escolar" (p.34). Dessa forma, para Forquin, o tempo escolar faz parte da cultura escolar, e finda por se inscrever na cultura da escola. Os elementos da cultura escolar estão inseridos em contextos e processos sócio-históricos específicos. A cultura da escola está inscrita nas rotinas, nos ritmos e ritos, na linguagem, no imaginário, nos modos de regulação ou transgressão e pode ser analisada tendo em vista duas dimensões para esse estudo: a dimensão das políticas, da história da escola e de seu funcionamento e a dimensão do cotidiano da escola. A cultura da escola expressa características universais, o que faz que a instituição escolar seja reconhecida como tal em qualquer lugar do mundo; mas também expressa características próprias, em razão de seus tempos e espaços, seus ritos, de seus agentes, dos valores atribuídos à escola pela sociedade em cujo contexto está inserida, que fazem que a cultura da escola expresse a singularidade de cada estabelecimento escolar.

Nessa perspectiva, a organização da escolaridade é, portanto, um produto da cultura da escola que define a organização dos tempos e espaços escolares marcados culturalmente, mas também social e historicamente, uma vez que não podem ser desconsideradas as inter-relações entre cultura, ideologia, política e economia. Nesse sentido, a implantação de um sistema de organização da escolaridade diferente da escola seriada há de considerar que as mudanças propostas interpelam os elementos da cultura da escola e que, portanto, podem não alterar a lógica do seu funcionamento, ou não modificar concepções em curto prazo. Propostas que rompem com a seriação, se não considerarem as culturas da escola bem como as culturas escolares, podem gerar alterações superficiais, incapazes de alterar a lógica da organização do trabalho escolar e mais, gerar conflitos e tensões no interior das escolas, conforme já apontaram alguns estudos (Fernandes, 2003). 
Entendemos que compreender como ocorreu a formação/organização da escola atual é importante para observar as possíveis alterações provocadas pela implementação dos ciclos.

\section{NA ESCOLA, A CONVIVÊNCIA DE DIFERENTES LÓGICAS}

Podemos dizer que a escola em ciclos, de um modo geral, tal como se apresenta hoje, conjuga lógicas de funcionamento, de práticas e concepções de seus agentes, que operam tanto em uma racionalidade coerente com as premissas de uma escola seriada quanto com as premissas de uma proposta de escola organizada em ciclos. A observação dos documentos oficiais, das Secretarias Municipais e Estaduais de Educação, e do MEC, por exemplo, os Parâmetros Curriculares Nacionais, revelam essa tensão. Também as concepções dos professores, expressas nas mais diversas situações, concorrem para essa afirmação.

A escola, para operar entre duas lógicas, conforma práticas de diferentes metodologias de ensino, isto é, um ensino ora com ênfase no que se ensina, ou seja, no programa, e ora com ênfase no que se aprende, portanto nas aprendizagens que os alunos realizam. Podemos encontrar inúmeros exemplos nas organizações escolares: concepção de avaliação contínua ou formativa no projeto pedagógico da escola e, na prática, a instituição de semana de provas; seleção de conteúdos ora baseada nos programas, ora baseada nas aprendizagens dos alunos etc.

A escola em ciclos administra conflitos. Se entendermos que o cotidiano escolar é marcado por urgências, por questões que muitas vezes não podem esperar, por relações humanas e que é, portanto, por natureza, complexo, podemos considerar que as tentativas de alterar práticas já consolidadas e legitimadas pela comunidade escolar e pela sociedade fazem que a escola em ciclos se torne, mais ainda, uma escola conflituosa.

Por ser a escola em ciclos uma escola da qual se exigem mudanças, ela se torna, mais do que as outras, uma escola inquieta, uma vez que toda sua organização - e porque não dizer, sua concepção - está sendo questionada: a forma de avaliar, a maneira de entender o conhecimento, a didática utilizada, a organização dos tempos e dos espaços, as relações em seu interior. Pois bem, essa escola solicita muito mais do corpo docente, no sentido de mobilizá-lo 
para encontrar soluções em conjunto, mediar estratégias, gerir situações curriculares, isto é, para decidir o que, por que, como e quando ensinar e avaliar. Tais demandas podem comprometer uma grande parte dos docentes com seu trabalho e com a construção de um projeto de escola que ainda está em construção (Fernandes, 2003). Com isso, podemos entender que tal movimento não se instaura apenas por ser uma escola em ciclos, mas por ser uma escola que se descobre necessitando mudar, uma escola inquieta, que está construindo algo novo. Podemos afirmar, dessa forma, que a implementação dos ciclos causa um movimento de inquietação saudável à necessária transformação de uma escola cuja cultura escolar e institucional foi balizada, desde sua origem, por uma ossatura rígida de organização de tempo e espaço, de conhecimento.

Por fim, podemos dizer que a possibilidade de transformação do habitus incorporaado pelos agentes de uma escola com uma lógica seriada para o habitus de uma escola "ciclada" se torna possível, na medida em que as disposições incorporadas são mutáveis e construídas socialmente, sendo a ordem social constituída por meio de estratégias e de práticas nas quais e pelas quais os agentes reagem, adaptam-se e constroem a história. Da mesma forma que foi construída uma lógica com base em uma cultura escolar seriada, que forneceu elementos para a constituição de uma disposição incorporada a partir dela, é possível imaginar que o habitus dos agentes pode se transformar à medida que novas práticas se incorporem à cultura da escola, instituindo uma nova lógica para a ordenação dos tempos e espaços escolares, para os conteúdos e seus tratamentos didáticos, como também para suas respectivas práticas avaliativas.

\section{CONSIDERAÇÕES FINAIS}

A superação do movimento pendular de responsabilizar pelo fracasso escolar, ora aos alunos e suas famílias, ora à escola e professores, bem como de atribuir a sua solução a mudanças pontuais nos sistemas de avaliação ou a alterações periféricas, é urgente. Também é urgente a superação da dicotomia estabelecida entre o discurso da qualidade do ensino da escola seriada ou a benevolência com a cultura dos alunos das classes populares da escola de ciclos. Sabemos que considerar um ensino de qualidade e, ao mesmo tempo, a cultura dos alunos não são aspectos inconciliáveis ou excludentes entre si. Procuramos, por uma análise do ponto de vista histórico-social e cultural, contribuir com 
elementos que nos ajudem a avançar no debate série/ciclos e compreender que tal dicotomia está a serviço da não superação do fracasso escolar.

Não podemos negar que as experiências que visam à não retenção dos alunos têm contribuído para a melhoria nos índices de evasão e para que um percentual maior de estudantes complete o ensino fundamental. Do ponto de vista social, é importante considerar essa questão. No entanto, uma vez dentro da escola, cabe-nos questionar e refletir sobre o que e como os estudantes estão aprendendo. Estudos apontam que o desempenho dos estudantes das escolas seriadas e das escolas em ciclos não deve ser associado de forma mecânica a este ou aquele tipo de organização ${ }^{5}$. Ou seja, nem o problema nem a solução se encontram na organização da escolaridade: série ou ciclo. Sem desprezar a importância da maneira pela qual se pode organizar a escolaridade, pois dela decorrem inúmeras e inestimáveis mudanças, as soluções para o fracasso escolar são de várias ordens, pois esse é gerado/criado por diferentes motivações. $\bigcirc$ debate sobre ciclos, apesar de, no Brasil, estar associado ao quadro de reprovação e sua necessária solução, não se dá apenas por esse fato. Dá-se pela urgência de se repensar uma escola que passe a considerar toda a complexidade do ensinar e aprender, bem como todas as mudanças no próprio mercado de trabalho e nas relações entre os sujeitos no mundo, entre si, com o tempo, com o espaço, com seus contextos de aprendizagem.

A superação de dilemas ou tensões clássicas em educação, como, por exemplo, a ideia da escola como espaço de reprodução ou de transformação, como espaço de manutenção dos padrões dos setores dominantes ou de ascensão das camadas da população menos privilegiadas faz-se urgente, uma vez que tais concepções ainda estão presentes na sociedade. A tentativa de superação desse pensamento dicotômico, bem como a compreensão do espaço escolar em toda a sua complexidade, já existe hoje em grande parte do discurso educacional. Precisamos, agora, incorporar o debate teórico às práticas existentes no cotidiano da escola.

Apontamos, portanto, que a qualidade da educação não passa pela opção de séries ou ciclos. Sabemos que a solução está associada a uma ação

5. Um estudo interessante acerca da proficiência de alunos sujeitos às políticas de promoção automática na Região Sudeste foi realizado por Ferrão, Beltrão e Santos (2002). Outro estudo está em Franco (2004). Uma discussão importante é feita em Freitas (2004). 
coordenada em diferentes âmbitos: sociais, culturais, educacionais, econômicos, políticos. No entanto, considerando que o ensino fundamental é direito de todos os alunos e dever da família e do Estado, se torna premente propor respostas ao problema. É responsabilidade do campo educacional e de seus profissionais apontar soluções em nível macro, no sentido mais amplo das formulações de políticas e ações, como também apresentar saídas do ponto de vista das práticas de ensino, envolvendo o planejamento das ações dos professores quanto à didática, à avaliação, ao currículo, e quanto às relações no interior da escola.

\section{REFERÊNCIAS BIBLIOGRÁFICAS}

BOURDIEU, P. O Poder simbólico. Rio de Janeiro: Bertrand Brasil, 1998.

. Razões práticas: sobre a teoria da ação. Campinas: Papirus, 1997.

FERNANDES, C. O. A Escolaridade em ciclos: práticas que conformam a escola dentro de uma nova lógica - a transição para a escola do século XXI. 2003. Tese (Doutorado) - Pontifícia Universidade Católica do Rio de Janeiro, Rio de Janeiro.

FERNANDEZ ENGUITA, M. A Face oculta da escola. Porto Alegre: Artes Médicas, 1989.

FERRÃO, M. E. B.; BELTRÃO, K. I.; SANTOS, D. P. Impacto das políticas de não repetência no desempenho acadêmico dos alunos da 4⿳亠口冋. série: modelagem multinível. Rio de Janeiro: PUC-Rio, 2002. (Relatório de pesquisa)

FORQUIN, J. C. Escola e cultura. Porto Alegre: Artes Médicas, 1993.

FRANCO, C. Ciclos e letramento na fase inicial do ensino fundamental. Revista Brasileira de Educação, Rio de Janeiro, n.25, p.30-38, 2004.

FREITAS, L. C. Ciclo ou séries? O que muda quando se altera a forma de organizar os tempos-espaços da escola? In: REUNIÃO ANUAL DA ANPED, 27., 21 -24 nov.2004, Águas de Lindoia. Anais... Águas de Lindoia: Anped, 2004. (GT I3: Educação fundamental). Disponível em: < http://www.anped.org.br/reunioes/27/diversos/te_luiz_carlos_freitas.pdf> . Acesso em: abr. 2008.

GIMENO SACRISTÁN, J. Escolarização e cultura: a dupla determinação. In: SILVA, L. et al. (Org.). Novos mapas culturais/novas perspectivas educacionais. Porto Alegre: Sulina, 1996. p.34-57. 
HAMILTON, D. Sobre as origens dos termos classe e curriculum. Teoria e Educação, Porto Alegre, n.6, p.33-52, 1992.

NÓVOA, A. Para uma análise das instituições escolares. In: NÓvOA, A. (Coord.). As Organizações escolares em análise. Lisboa: Dom Quixote, 1995. p. I-8.

PÉREZ GÓMEZ, A. La Cultura escolar en la sociedade posmoderna. Cuadernos de Pedagogia, Barcelona, n.225, p.80-85, 1994.

. A Cultura escolar na sociedade neoliberal. Porto Alegre: Artmed, 2001 .

PERIN, P. H. P.; LAPLANE, A. L. F. Progressão continuada no Estado de São Paulo: 30 anos de debate educacional. In: ENCONTRO DE PESQUISA EM EDUCAÇÃO DA REGIÃO SUDESTE-ANPED, 5. , 2002, Águas de Lindoia. Anais... Águas de Lindoia: 2002. CD-ROM. PINTO, J, M. S. O Tempo e a aprendizagem: subsídios para uma nova organização do tempo escolar. Porto: ASA, 2001.

Recebido em: maio 2008

Aprovado para publicação em: setembro 2009 